Fountain Journal of Natural and Applied Sciences 2016; 5(2): 31-36
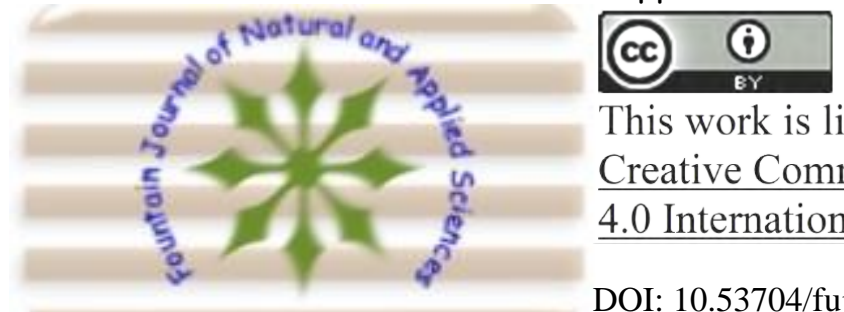

This work is licensed under Creative Commons Attribution 4.0 International License.

DOI: 10.53704/fujnas.v5i2.158

A publication of College of Natural and Applied Sciences, Fountain University, Osogbo, Nigeria.

Journalhomepage:www. fountainjournals.com

ISSN:2354-337X(Online),2350-1863(Print)

\title{
Storage Stability of Ascorbic Acid Content of Nigerian Processed Fruit Juices.
}

\author{
${ }^{{ }^{1}}$ Mohammed, A.A., ${ }^{2}$ Adewuyi, G.O., ${ }^{3}$ Ademoyegun, O.T. \\ ${ }^{1}$ Department of Industrial Chemistry, University of Ilorin, Ilorin, Nigeria. \\ ${ }^{2}$ Department of Chemistry, University of Ibadan, Ibadan \\ ${ }^{3}$ National Horticultural Research Institute, Ibadan, Oyo State, Nigeria
}

\begin{abstract}
Ascorbic acid is an essential vitamin derived from fruits and vegetables for human growth. This study investigated the ascorbic acid contents of juice extracts and its rate of loss in fresh fruits and stored fruits, specifically pineapple, water melon, grape and orange. Fruits were extracted by electric juice extractor, and each fruit juice extracted was divided to two groups. The First group were refrigerated in PET and glass bottle at $-4^{\circ} \mathrm{C}$ for one month While the second group were stored at room temperature with and without preservative (sodium benzoate). Commercial fruit juices commonly sold in the market were also refrigerated at $-4^{\circ} \mathrm{C}$ for 13 days. The physical parameters (Brix and $\mathrm{pH}$ ) were determined on each of the fresh fruit juices using a refractometer and $\mathrm{pH}$ metre. The general outcome of this study revealed that the rate at which ascorbic acid is lost during storage depends on the type of fruit, storage condition and duration of storage.

Keywords: Ascorbic acid, Fruit, Juice storage, Iodometry
\end{abstract}

\section{Introduction}

Human nutrition is not complete without vitamin $C$ as part of the diets. Ascorbic acid is commonly found in fruits and vegetables based products. The availabilities of fruits and vegetables are often affected by seasonal variations. Hence, fruits are sometimes preserved and at times juices are extracted, processed and packaged as Can juice that is sold in the public. Different preservatives were usually used to extent the shelf life of fruits and reduces it spoilage such as sodium benzoate, citric acid, potassium sorbate, sodium metabisulfite among others. Ascorbic acid is a water-soluble vitamin responsible for the stimulation of the immune system, curing of arteriosclerosis, cardiovascular diseases and some forms of cancer
(Ojo et al., 2013). Vitamin $C$ is to be consumed on a daily basis due to its ability to be washed away through stress (Olivier, 2004).

In Nigeria, we are blessed with lots of fruits and vegetables due to the nature of our soil, which make it possible for agricultural practice. The amount of vitamin $C$ contents varies in different fruits and vegetables depending on the storage condition and production factors. Human beings do not synthesize vitamin $C$ by themselves, but they can get it through the intake of fruits, vegetables and vitamin supplements (Bello and Fowoyo, 2014). Fruits eaten raw contain enough vitamin $C$ than eaten cooked

*Corresponding author: +2348068302379

Email address: tiwatope1302@gmail.com 
Fountain Journal of Natural and Applied Sciences 2016; 5(2): 31-36

vegetables in which most of the vitamin $C$ has been a loss due to boiling (Ojo et al., 2013).

Different methods have been studied by various researchers for determination of ascorbic acid in different fruits and vegetables such as Titrimetry (Ajibola et al., 2009; Bello and Fowoyo, 2014; Collins et al, 1999; Kabasakalis et al., 2000), UV spectroscopy ( Rahman et al., 2006; Macie and Krzysztof, 2007; Ahmed 2013), Polarographic (Swaroopa, 2015), High-performance liquid chromatography (Zbynek et al., 2008), Cyclic voltametry (Okiei et al., 2009) amperometry (Arya et al., 2000). The study of ascorbic acid in fruits and vegetables is important to consumers who must know the container to store fruit juices, how to store juice containers and if preservative can retain ascorbic acid in fruit juices. The objectives of this work were to determine the ascorbic acids content of some processed fruit's juices; to measure the amount of ascorbic acid lost under different storage containers namely, pet and glass bottles containers, also to evaluates the effects of preservatives (sodium benzoate) on the content of an ascorbic acid stores under ambient condition and loss of ascorbic acid on commercial pineapple juice, which were stored in close cap and open cap condition.

\section{Materials and Methods}

\section{Chemicals and Reagents}

The reagents used were Ascorbic acid Standard, Potassium Iodide KI, Potassium Iodate $\mathrm{KIO}_{3}$, Sulphuric acid $\mathrm{H}_{2} \mathrm{SO}_{4}$, Iodine Solution, Sodium Benzoate, 1\% Starch Indicator. All the reagents were of analytical grade.

\section{Sample collection and Preparation}

Fresh Samples of Orange, Water melon, Pineapple, Sweet grapes were collected freshly from National Horticultural Research Institute in Ibadan, Oyo State, Nigeria. Also, In addition, Commercial fruit juices were purchased from Bodija Market in Ibadan, Oyo State. The fresh fruit samples were peeled and washed. It was extracted freshly on the same day of purchase with an electric juice extractor. The fruit juice samples were then divided to two groups. The first group were stored at the refrigerator for- $4^{\circ} C$ using PET (polyethylene bottles) and glass bottles for one month. While the second group were stored at room temperature with preservative (using sodium benzoate) and without preservative for 7 days. Commercial pineapples were refrigerated at $-4^{\circ} \mathrm{C}$ with open cap and close cap for 13 days. The $\mathrm{pH}$ and total soluble solid (brix) were determined using $\mathrm{pH}$ meter and refractometer.

\section{Preparation of Solutions}

One-percent starch indicator solution was prepared by adding $0.50 \mathrm{~g}$ of soluble starch in $50 \mathrm{~mL}$ of near-boiling water. Iodine solution was prepared by dissolving $1.0 \mathrm{~g}$ of potassium iodide (KI) and 0.05 $g$ of potassium iodate $\left(\mathrm{KIO}_{3}\right)$ in $200 \mathrm{~mL}$ of water followed by addition of $3 \mathrm{M}$ sulphuric acid. The solution was made up to $500 \mathrm{~mL}$ in a graduated cylinder and then transferred into a beaker. Vitamin $C$ standard solution was prepared by dissolving $0.1 \mathrm{~g}$ of vitamin $C$ in $100 \mathrm{~mL}$ of distilled water and then stored in a glass stopper bottle as a stock solution (Ajibola et al., 2009).

\section{Standardizing Ascorbic acid with Iodine Solution}

$10 \mathrm{ml}$ of Ascorbic acid standard solution and 2 drop of $1 \%$ starch solution was added to $100 \mathrm{ml}$ volumetric flask and titrated against iodine solution. At the end point, there was a blue-black colour which persists after 20 seconds (Ajibola et al., 2009).

\section{Determination of Ascorbic acid in the Sample}

$10 \mathrm{ml}$ of each of the fruit juice samples was measured into pre- washed conical flask and titrated against iodine solution until a blue-black colour that persists longer than 20 seconds marked the end point of the reaction. The titration was repeated thrice (Ajibola et al., 2009). The reaction between Ascorbic acid and Iodine was given as;

$\mathrm{C}_{6} \mathrm{H}_{8} \mathrm{O}_{6}(\mathrm{aq})+\mathrm{I}_{2}$ (aq) $\rightarrow \mathrm{C}_{6} \mathrm{H}_{6} \mathrm{O}_{6}$ (aq) $+2 \mathrm{I}^{-}$(aq) $+2 \mathrm{H}^{+}$

\section{Results and discussion}

Physical Parameters Checked on the Fruit Juice Samples

The $\mathrm{pH}$ of all the fruit samples used for this study ranged from 3.10-5.10 and total soluble solid (Brix) ranges from 7.00-15.00 as shown in table 1 
Fountain Journal of Natural and Applied Sciences 2016; 5(2): 31-36

below. Pineapple has the lowest $\mathrm{pH}$ value while the water melon has the lowest $\mathrm{pH}$ value which indicated that it is very acidic compared to the other juice used for this analysis. Moreover, pineapple juice has the highest total soluble solid (Brix) which indicated its sweetness and water melon has a lowest value for total soluble solid.

Comparison were also made in Figure 1 showing Grape and Orange at room temperature with preservative using Sodium Benzoate and without Preservative at room temperature for 7 days. Sweet Grape at room temperature loss 7.98$15.95 \%$ of ascorbic acid content with preservative (sodium benzoate) and $13.86-20.59 \%$ without preservative for 7 days. Preservatives are employed as part of food additive in order to extent the shelve life of fruit juices. It has been reported that reaction of preservatives can cause allergies, asthma and skin rashes, headache, cancer, palpitations, urticaria and contact dermatitis (Kinderlerer \& Hatton, 1990).

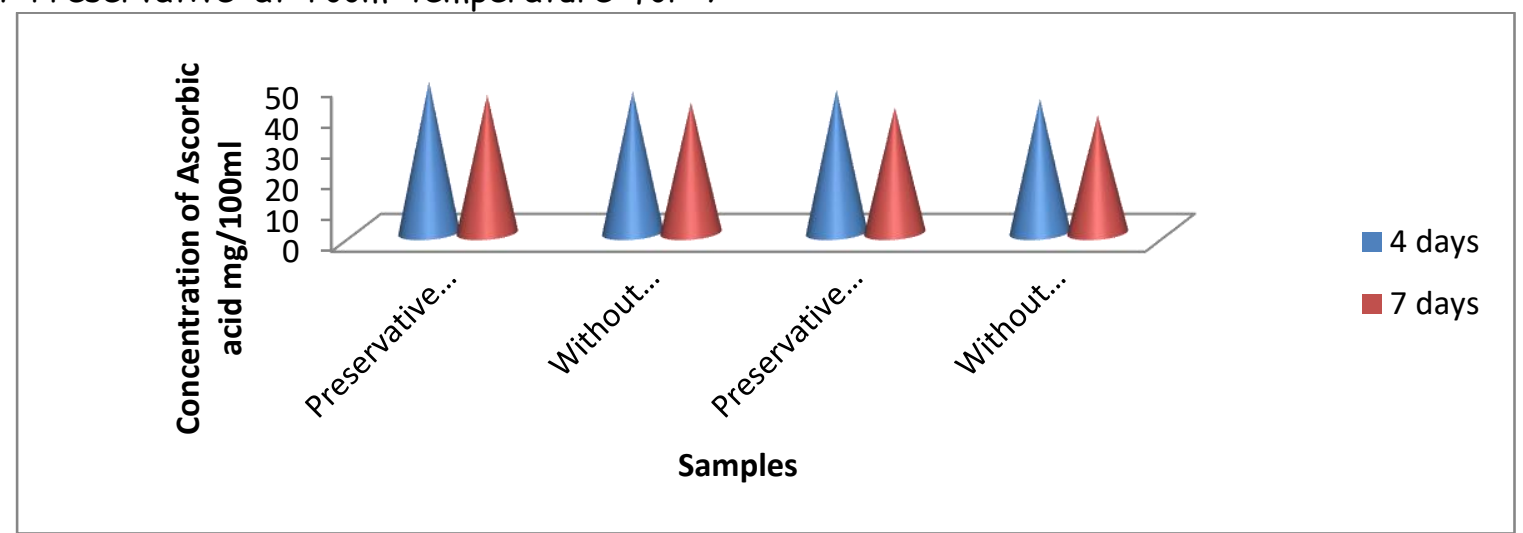

Figure 1 : Ascorbic acid content of orange juice stored at room temperature with preservative and without preservative

Table 1: The pH and Total Soluble Solid of all the Juice Samples Analysed

\begin{tabular}{lll}
\hline Fruit juice & $\mathrm{pH}$ of the juice & Total soluble solid (Brix) \\
\hline Pineapple & 3.60 & 15.00 \\
Water melon & 5.10 & 7.00 \\
Grape & 3.40 & 11.75 \\
Orange & 3.90 & 12.00 \\
Canned Pineapple juice & 3.10 & 14.00 \\
\hline
\end{tabular}

Table 2: Ascorbic Acid values in Orange and Sweet grape freshly Produced juice, both stored in PET and Glass Bottle refrigerated for 31 days

\begin{tabular}{lllll}
\hline Days & $\begin{array}{l}\text { \% Loss of } \\
\text { Ascorbic acid } \\
\text { contents in Orange } \\
\text { (PET Bottle) }\end{array}$ & $\begin{array}{l}\text { \% Loss of } \\
\text { Ascorbic acid } \\
\text { contents in } \\
\text { Orange(Glass Bottle) }\end{array}$ & $\begin{array}{l}\text { \% Loss of } \\
\text { Ascorbic } \\
\text { acid contents } \\
\text { in Sweet } \\
\text { Grape (PET } \\
\text { Bottle) }\end{array}$ & $\begin{array}{l}\text { \% Loss of } \\
\text { Ascorbic acid } \\
\text { contents in Sweet } \\
\text { Grape (Glass Bottle) }\end{array}$ \\
\hline 1 & 0 & 0 & 0 \\
4 & 1.37 & 3.22 & 0.62 & 2.52 \\
7 & 4.59 & 5.97 & 3.36 & 5.73 \\
10 & 9.16 & 10.54 & 6.73 & 8.02 \\
13 & 14.68 & 19.26 & 11.35 & 12.61 \\
16 & 21.10 & 22.48 & 16.80 & 18.05 \\
19 & 27.99 & 29.37 & 23.52 & 24.87 \\
22 & 35.32 & 36.69 & 31.94 & 33.20 \\
25 & 44.03 & 45.43 & 41.16 & 42.44 \\
28 & 53.67 & 55.52 & 52.09 & 53.35 \\
31 & 65.14 & 66.51 & 63.85 & 65.11 \\
\hline
\end{tabular}


Fountain Journal of Natural and Applied Sciences 2016; 5(2): 31-36

Table 3: Values of Ascorbic Acid in Pineapple

Fresh Produced juice, both stored in PET

And Glass Bottle refrigerated for 19 days

\begin{tabular}{lll}
\hline Days & $\begin{array}{l}\text { \% Loss of Ascorbic } \\
\text { acid contents in } \\
\text { Pineapple (PET } \\
\text { Bottle) }\end{array}$ & $\begin{array}{l}\text { \% Loss of Ascorbic acid } \\
\text { Contents in Pineapple } \\
\text { (Glass Bottle) }\end{array}$ \\
\hline 1 & 0 & 0 \\
4 & 5.55 & 7.37 \\
7 & 12.99 & 18.54 \\
10 & 24.09 & 27.81 \\
13 & 37.09 & 40.81 \\
16 & 57.37 & 62.91 \\
19 & 77.81 & 83.36 \\
\hline
\end{tabular}

Table 4: Values of Ascorbic Acid in Water Melon

Fresh Produced juice, both stored in

PET and Glass Bottle refrigerated for 16 days

\begin{tabular}{lll}
\hline Days & $\begin{array}{l}\text { \% Loss of Ascorbic acid } \\
\text { contents in Water } \\
\text { Melon (PET Bottle) }\end{array}$ & $\begin{array}{l}\text { \% Loss of Ascorbic } \\
\text { acid contents in } \\
\text { Water Melon (Glass } \\
\text { Bottle) }\end{array}$ \\
\hline 1 & 0 & 0 \\
4 & 10.59 & 15.88 \\
7 & 21.06 & 26.35 \\
10 & 34.24 & 39.41 \\
13 & 50.00 & 57.88 \\
16 & 68.47 & 76.35 \\
\hline
\end{tabular}

Table 5: Values of Ascorbic Acid in Commercial Pineapple juice refrigerated for 13 days

\begin{tabular}{lll}
\hline Days & $\begin{array}{l}\text { \% Loss of } \\
\text { Ascorbic acid } \\
\text { contents in } \\
\text { Commercial } \\
\text { Pineapple } \\
\text { Cap ) }\end{array}$ & $\begin{array}{l}\text { \% Loss of } \\
\text { Ascorbic acid } \\
\text { contents in } \\
\text { Commercial } \\
\text { Pineapple (Open } \\
\text { Cap) }\end{array}$ \\
1 & 0 & \\
4 & 5.79 & 17.63 \\
7 & 17.63 & 32.24 \\
10 & 32.24 & 46.97 \\
13 & 52.89 & 67.63 \\
\hline
\end{tabular}

Ascorbic acid contents of Commercial pineapple juice losses $5.79-52.89 \%$ and $17.63-$ $67.63 \%$ in close cap and open cap respectively for 13 days as shown in Table 5 above. Open cap means the cover of the commercial pineapple was removed and close cap means the cover was not removed. As reported by Ajibola et al (2009) and Kabasakalis et al (2000) the storage condition, container types and days of storage of fruit juices usually affect the Contents of ascorbic acid commonly consumed.

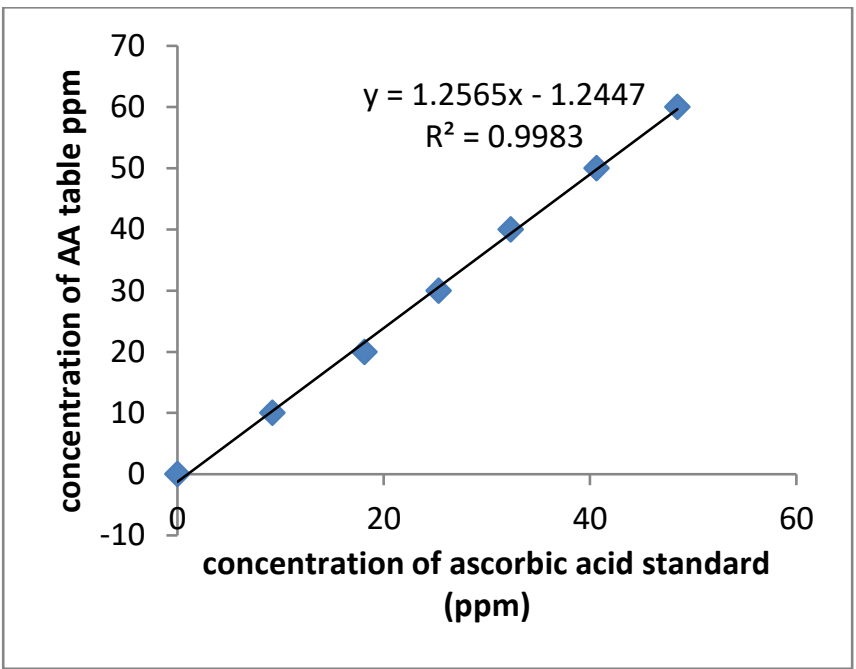

Figure 2: Correlation analysis of Ascorbic acid tablet (ppm) vs Concentration of ascorbic acid Standard (ppm)

The deviation of these results from those reported by some other researchers for some of the fruit samples analyzed may be as a result of the other factors that affect the ascorbic acid level in fruits. These factors include climate, the degree of ripeness and the amount of fertilizer used in the cultivation (Dioha et al., 2011). The accuracy and Precision of ascorbic acid were determined by comparing the measured vitamin $C$ Standard and measured Vitamin $C$ tablet using Titration method for the analysis. The results were presented in correlation analysis in Figure 2 below. The coefficient of correlation was 0.998 and a linear regression had an intercept of 0 and a slope of 1

\section{Recovery Study}

A know amount of ascorbic acid standard was added to three replicates of each fruit juice that were determined for this analysis using oxidationreduction titration as shown in Table 6 below which shows the precision and recovery of this method. Both results gave strong evidence that the oxidative- reduction titration is accurate and reliable for the routine determination of ascorbic acid in fruit juices. . 
Table 6: Recovery Study and Co-Efficient of Variation (Cv)

\begin{tabular}{|c|c|c|c|c|c|}
\hline Sample & Initial & Amount Spike & Amount Recovery & $C v$ & \% Recovery \\
\hline \multirow[t]{3}{*}{ Grape } & 33 & 50 & 82 & 0.77 & 98 \\
\hline & 33 & 100 & 131 & & 98 \\
\hline & 33 & 150 & 178 & & 96.7 \\
\hline \multirow[t]{3}{*}{ Orange } & 28.2 & 50 & 76 & 0.86 & 95.6 \\
\hline & 28.2 & 100 & 125 & & 96.8 \\
\hline & 28.2 & 150 & 175 & & 97.2 \\
\hline \multirow[t]{3}{*}{ Pineapple } & 4.8 & 50 & 53 & 0.59 & 96.4 \\
\hline & 4.8 & 100 & 102 & & 97.2 \\
\hline & 4.8 & 150 & 151 & & 97.5 \\
\hline \multirow[t]{3}{*}{ Water Melon } & 2.0 & 50 & 51 & 0.52 & 98 \\
\hline & 2.0 & 100 & 99 & & 97 \\
\hline & 2.0 & 150 & 148 & & 97.3 \\
\hline Commercial & 1.8 & 50 & 50 & 0.31 & 96.4 \\
\hline \multirow[t]{2}{*}{ Pineapple juice } & 1.8 & 100 & 98 & & 96.2 \\
\hline & 1.8 & 150 & 147 & & 96.8 \\
\hline
\end{tabular}

\section{Conclusion and Recommendation}

Many different methods can be used to determine the vitamin $C$ content in juices. Iodometry titration was used in this research because it is less expensive, highly precise and accurate. This study tested different types of available natural fruit juice samples to compare the amount of vitamin $C$ in each type of container. The order of Vitamin C contents of Fruit juice recorded in the order Sweet Grape > Orange > Pineapple > Water melon > Commercial Pineapple juice. Apparently, from this study, fruit samples stored in PET bottles retained ascorbic acid better than those in glass bottles. Commercial Pineapple juice in close cap yielded a more ascorbic acid than those in open cap refrigerated for the same period of time. This means that the overall nutritional quality of fruit juices is affected by storage. The only variable in the samples used was the container that the samples were stored in. Fruit sample must not be kept for a long time because ascorbic acid contents in fruits are not stable and are easily oxidized. Adequate consumption of a different kind of fruit is good for the body because it can prevent the body from a different kind of dangerous diseases such as stroke, diabetes, cancer, atherosclerosis, glaucoma and various diseases that are prevalent in Africa
(Dioha et al., 2011). It is therefore recommended that fresh fruits be taken by consumers within the first three days of harvest and canned fruit juices be taken within a minimum of four days after opening the can.

\section{References}

Ahmed Z.M.H (2013). Spectrophometric determination of ascorbic acid in aqueous solutions and in pharmaceuticals formulation. Journal of AlNahrain University 16(3), 65 - 71.

Ajibola V.O., Babatunde O.A., \& Suleiman S. (2009). The Effect of Storage Method on the Vitamin C Content in Some Tropical Fruit Juices. Trends in Applied Sciences Research 4, 79-84.

Arya S.P, Mahajan M., \& Jain P. (2000). Nonspectrophometric methods for the determination of vitamin $C$ .AnalyticaChimica Anta 417, 1 - 14.

Bello A.A., \& Fowoyo P.T. (2014). Effect of heat on the ascorbic acid content of dark green leafy vegetables and citrus fruits. African Journal of Food Sci. and Techn. 5(4), 114118. 
Fountain Journal of Natural and Applied Sciences 2016; 5(2): 31-36

Collins, C. H., Silva, C. R., Simoni, J. A., \& Volpe, P. L. O.(1999). Ascorbic acid as a Standard for Iodometric Titrations. Journal of Chemistry Education 76, 1421 - 1422.

Dioha, I.J., Olugbemi, O., Onuegbu, T.U \& Shahru Z. (2011).Determination of ascorbic acid Content of some tropical fruits by iodometric titration. Journal of Biological and Chemical Science. 5(5), 2180 - 2184.

Kabasakalis, V., Siopidou, D., \& Moshatou, E. (2000). Ascorbic acid content of commercial fruits juices and its rate of loss upon storage. Food Chemistry 70, 325 - 328.

Kinderlerer, J.L. \& Hatton, P. (1990). Fungal metabolites of sorbic acid. Food AdditContam. 7(5), 657-669.

Maciej R. \& Krzysztof G. (2007). Modification of spectrophotometric methods for antioxidative vitamins determinant convenient in analytic practice. Anta. Scientiarumpolonorum. TechnologiaAlimentaria6(3), 17 - 28

Ojo R.J , Abaya J.Y ,Akintayo C.O, \& Seriki S. (2013).effects of Nigerian market storage conditions on ascorbic acid contents of selected tetrapak packaged citrus fruit juice Journal of Agricultural and Biological Sciences. 8(2), 179-183.
OkieiW, Ogunlesi, M. Azeez, L., Obakachi, V., Osunsanmi, M., \& Nkenchor G. (2009). The voltammetric and titrimetric determination of ascorbic acid levels in tropical fruit samples. International Journal Electrochemical Science 4, 276 - 287

Olivier F. (2004). Musculoskeletal manifestations of scurvy. Review Joint Bone Spine. 72, 124 128

Rahman M.M.K, Rahman M.M, Islam M.S, \& Begum S.A (2006). A simple uv spectrophotometric method for determination of vitamin $c$ in various fruits and vegetables at sylhet area of Bangladesh. Journal of biological sciences 6, 388-392

Swaroopa R.N (2015). Polarograhicmethods for determination of ascorbic acid in pharmaceutical preparations. Int. Journal. of chemical engineering and applications 6(2), $75-80$

Zbynek G., Ondrej Z., Jitka P., Vojtech A., Josef Z., Ales H., Vojtech Z.,Miroslava B., \& Rene K. (2008). Determination of Vitamin $C$ (ascorbic acid) using High performance liquid chromatography coupled with electrochemical detection. Sensor 8, 70977112 . 